\title{
Analysis on surrounding rock masses' stabilities for underground cavern group
}

\author{
Song Shu-guang ${ }^{1, a}$, Sun Chao-qun ${ }^{1, b}$ and Chen Yun-juan ${ }^{1, c}$ \\ ${ }^{1}$ Geotechnical and Structural Engineering Research Center, Shandong University, Ji'nan 250061, \\ China. \\ atwilightsong@126.com, b312114642@qq.com, c1565421691@qq.com
}

Keywords: hydropower station; surrounding rock; supporting design; crane beam

\begin{abstract}
Surrounding rock masses' stabilities of cavities and crane beams of the hydropower station were studied using FLAC $^{3 \mathrm{D}}$. Results show that, due to the large excavation span and height, the main powerhouse and tail water hole have larger plastic zones after the excavation, and the same as 1 \# unit and 2 \# unit affected by the alteration belt; after the excavation, the plastic zones of the main powerhouse and main transformer hole appear connected and it is reduced obviously after support; from the comprehensive consideration of cavities' stabilities and economic benefits, scheme 3 ( bolts and nineteen cables ) is the optimal supporting plan, apt to ensure the overall stability of surrounding rock; displacements of surrounding rock and bolts' axial forces of crane beams are caused mainly by excavation, while the parts caused by wheel pressure are small. This offers a reliable basis for stability analysis and supporting design for underground cavern group.
\end{abstract}

\section{Introduction}

The hydropower station is located in Sichuan province, China. Its total installed capacity is 219.7 million $\mathrm{m}^{3}$. The underground powerhouse systems are mainly composed of main powerhouse, main transformer hole, tail water hole, bus tunnel and tail pipes. The main powerhouse's excavation size is $170 \mathrm{~m} \times 23.4 \mathrm{~m} \times 60.7 \mathrm{~m}$ (length $\times$ width $\times$ height) and the roof's excavation elevation is $2024.8 \mathrm{~m}$, its largest excavation span is $24.9 \mathrm{~m}$ and its largest excavation height is $60.7 \mathrm{~m}$. The tail pipe bottom's excavation elevation is $1964.1 \mathrm{~m}$. The main transformer hole is located between the main powerhouse and the tail water hole, it is $40 \mathrm{~m}$ far away from the main powerhouse and its excavation size is 114.7 $\mathrm{m} \times 17.3 \mathrm{~m} \times 22.2 \mathrm{~m}$ ( length $\times$ width $\times$ height ). The main powerhouse and the main transformer hole is connected by the bus tunnel and its net section size is $7.5 \mathrm{~m} \times 6.8 \mathrm{~m}$ (width $\times$ height).

Overlying rock's thickness of The underground cavern group is $112 \sim 339 \mathrm{~m}$, the surrounding rock masses are mainly quartzite and marble, giving priority to $\mathbb{I}_{1}$ class and locality class, there are some small faults such as f1, f3, f4, f17 etc. The engineering geological conditions are comprehensively analyzed of underground powerhouse area, it is good and most surrounding rock is stable, the area has the condition of building underground caverns with large span, of course, local parts with bad stability or instability need to be supported.

The hydropower station is deep in the rock mass, the cavities have complex layout and the stability of cavern surrounding rock after excavation needs to be targeted researched. With reference to the design and construction experience of similar underground engineering at home and abroad ${ }^{[1-4]}$, the mechanical analysis model is established in this paper combined with complex topography and geology condition, rock mass structure, physical and mechanical characteristics of surrounding rock. Surrounding rock masses' stabilities of cavities, crane beam's stabilities are studied using FLAC ${ }^{3 \mathrm{D}}$, which offers a reliable basis for the stability analysis and supporting design for underground powerhouse cavern group. 


\section{Analysis on reasonable supports of underground cavern group}

The calculation coordinate system is the right-handed coordinate system, defined as follows: $\mathrm{X}$ axis is perpendicular to the workshops' longitudinal direction, the positive direction is from upstream to downstream; $\mathrm{Y}$ axis is the vertical direction and the positive direction is upward and $\mathrm{Z}$ axis is parallel to the workshops' longitudinal direction. During the modeling process, faults with larger effect on the stability of caverns, such as f1, f3, f4, f17 and alteration belt are considered. The three dimensional model is divided into 324391 units and 55407 nodes, three dimensional element subdivision graph and the hydraulic structure model are shown as Fig. 1 and Fig. 2. Z coordinates of 1 \#, 2 \#, 3 \# and 4 \# units are 106.35 m, 81.35 m, 56.35 m, 31.35 m, respectively.

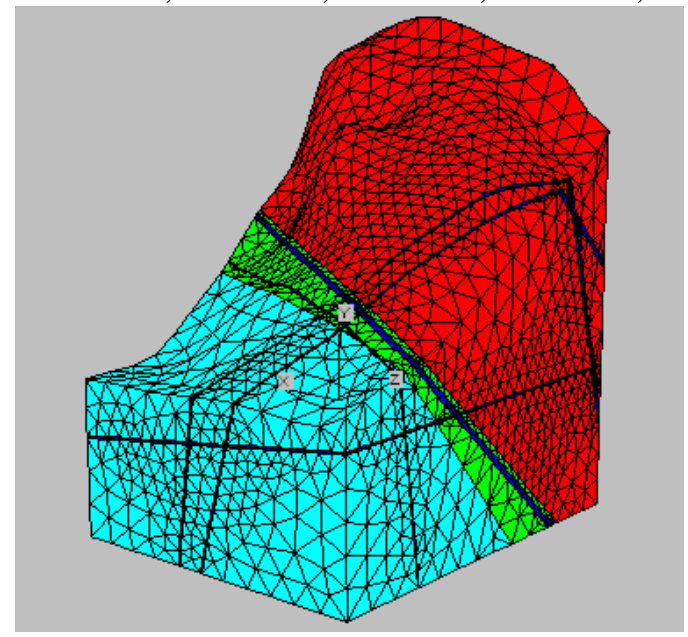

Fig. 1 Three dimensional element subdivision graph

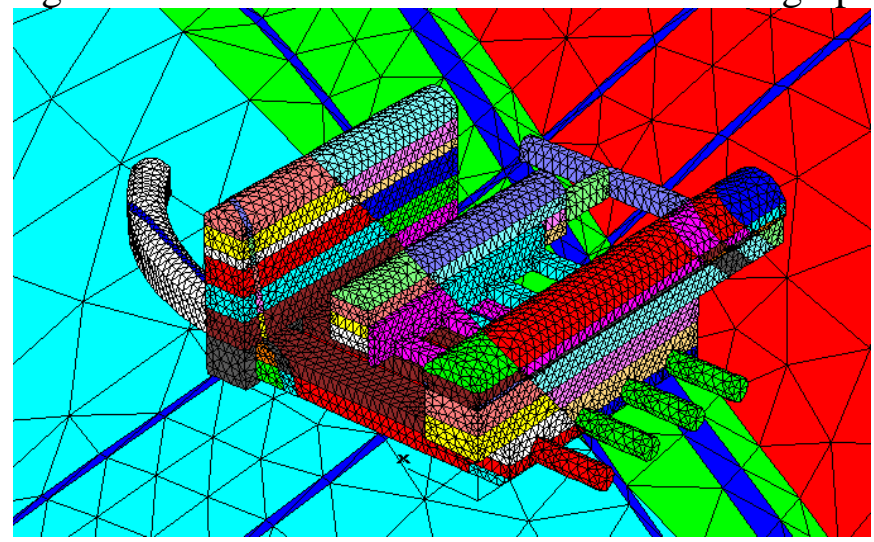

Fig. 2 Three dimensional hydraulic structure model

Take 2 \# unit model for designing supporting parameters of underground caverns. Four support schemes have been designed ${ }^{[5-7]}$ :

(1) scheme 1 ( only bolt supports and there are no cables ). Scheme 2, 3 and 4 have increased cables based on the scheme1, and the layouts of cables are as follows:

(2) scheme 2

There are four rows of cables in the upstream of the main powerhouse and three rows of cables in the downstream; there are only one row of cable in both the upstream and downstream of the main transformer hole; there are three rows of cables in the crown of the tail water hole, and six rows of cables in both the upstream and downstream.

(3) scheme 3

There are four rows of cables in the upstream of the main powerhouse and five rows of cables in the downstream; there are five rows of cables in both the upstream and downstream of the tail water hole. 
(4) scheme 4

There are five rows of cables in the upstream of the main powerhouse and seven rows of cables in the downstream; there are five rows of cables in both the upstream and downstream of the tail water hole.

The plastic zone sizes of these four support schemes are shown in Table 1. From it we can see that: the total plastic zone size of scheme 2 is $39878.0 \mathrm{~m}^{3}$, and has reduced by $14.6 \%$, compared to 46681.8 $\mathrm{m}^{3}$ of scheme 1 , the plastic zone size of main powerhouse has reduced by $11.6 \%$, the plastic zone size of main transformer hole has reduced by $6.75 \%$, the plastic zone size of tail water hole has reduced by $32.0 \%$; the total plastic zone size of scheme 3 is $38687.4 \mathrm{~m}^{3}$, and has reduced by $17.1 \%$, compared to $46681.8 \mathrm{~m}^{3}$ of scheme 1 , the plastic zone size of main powerhouse has reduced by $28.4 \%$, the plastic zone size of main transformer hole has reduced by $13.5 \%$, the plastic zone size of tail water hole has reduced by $17.4 \%$; the total plastic zone size of scheme 4 is $38463.1 \mathrm{~m}^{3}$, and has reduced by $17.6 \%$, compared to $46681.8 \mathrm{~m}^{3}$ of scheme 1 , the plastic zone size of main powerhouse has reduced by $29.7 \%$, the plastic zone size of main transformer hole has reduced by $13.5 \%$, the plastic zone size of tail water hole has reduced by $17.7 \%$. From the point of supporting effect, scheme 3 and scheme 4 are better than scheme 2, while, considering the restriction of economics, scheme 3 is the best of these four support schemes due to its good supporting effect and less cables.

Table 1 Plastic zone sizes of four support schemes $\left[\mathrm{m}^{3}\right]$

\begin{tabular}{ccccc}
\hline Parts & Scheme 1 & Scheme 2 & Scheme 3 & Scheme 4 \\
& & & & \\
\hline Total plastic zone sizes & 46681.8 & $39878.0 /-14.6 \%$ & $38687.4 /-17.1 \%$ & $38463.1 /-17.6 \%$ \\
Main powerhouse & 14693.6 & $12984.3 /-11.6 \%$ & $10522.4 /-28.4 \%$ & $10331.5 /-29.7 \%$ \\
Main transformer hole & 10965.5 & $10224.9 /-6.75 \%$ & $9490.1 /-13.5 \%$ & $9490.2 /-13.5 \%$ \\
Tail water hole & 13440.3 & $9136.7 /-32.0 \%$ & $11098.8 /-17.4 \%$ & $11065.3 /-17.7 \%$ \\
\hline
\end{tabular}

\section{Stability analysis of crane beam on rock wall}

There are eight wheels on each side of the crane beam on rock wall of the hydropower station. In the excavation and normal operation period, the wheel pressure value is $580 \mathrm{KN}$ and the horizontal force is $110 \mathrm{KN}$. The wheel pressure is $640 \mathrm{KN}$ and the horizontal force is neglected in the overload operation period. Crane beam on rock wall is shown in Fig. 3. There are three bolts near the abutment at each side of the crane beam, bolt spacing is $0.75 \mathrm{~m}$.

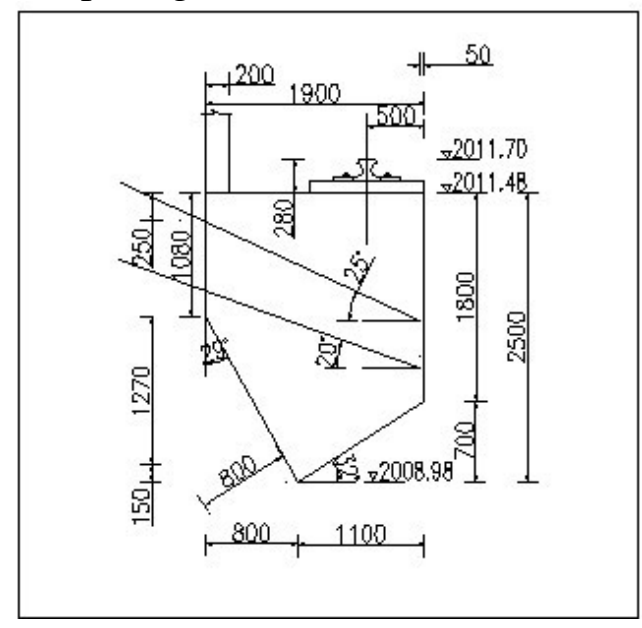

Fig. 3 Layouts of crane beam

Take 2 \# unit for example, the calculation model is divided into 170728 elements and 30881 nodes, and the grids of crane beam is refined. Loads are applied to the crane beam when the eight excavation and support is finished. The wheel pressure applied to the crane beam is equivalent to uniform $\operatorname{load}^{[8,9]}$. The calculation parameters are shown in Table 2. 
Table 2 Physical and mechanical parameters of crane beam and surrounding rock

\begin{tabular}{ccccccc}
\hline Rock type & $\begin{array}{c}\text { Density } \\
{\left[\mathrm{g} / \mathrm{cm}^{3}\right]}\end{array}$ & $\begin{array}{c}\text { Elastic modulus } \\
{[\mathrm{Gpa}]}\end{array}$ & $\begin{array}{c}\text { Poisson } \\
\text { ratio }\end{array}$ & $\begin{array}{c}\text { Cohesion } \\
{[\mathrm{Mpa}]}\end{array}$ & $\begin{array}{c}\text { Friction angle } \\
{\left[{ }^{\circ}\right]}\end{array}$ & $\begin{array}{c}\text { Tensile strength } \\
{[\mathrm{Mpa}]}\end{array}$ \\
\hline $\begin{array}{c}\text { Surrounding } \\
\text { rock }\end{array}$ & 2.81 & 7 & 0.28 & 0.8 & 40 & 5.0 \\
concrete & 2.50 & 30 & 0.167 & 1.75 & 20 & 1.4 \\
\hline
\end{tabular}

Table 3 Displacements and bolts’ axial forces of crane beam

\begin{tabular}{|c|c|c|c|c|c|c|c|c|c|c|c|}
\hline & & $\begin{array}{c}\text { Step } \\
1\end{array}$ & $\begin{array}{c}\text { Step } \\
2\end{array}$ & $\begin{array}{c}\text { Step } \\
3\end{array}$ & $\begin{array}{c}\text { Step } \\
4\end{array}$ & $\begin{array}{l}\text { Step } \\
5\end{array}$ & Step 6 & Step 7 & $\begin{array}{l}\text { Step } \\
8\end{array}$ & $\begin{array}{l}\text { Normal } \\
\text { operation }\end{array}$ & $\begin{array}{r}\text { Overload } \\
\text { operation }\end{array}$ \\
\hline \multirow{4}{*}{$\begin{array}{l}\text { Displace } \\
\text { ments of } \\
\text { crane } \\
\text { beam/mm }\end{array}$} & Upstream & 4.60 & 8.91 & 18.57 & 23.65 & 32.20 & 35.90 & 38.80 & 39.52 & 39.79 & 39.80 \\
\hline & Downstream & 1.89 & 5.14 & 6.04 & 6.63 & 7.09 & 8.33 & 10.34 & 10.63 & 11.01 & 11.03 \\
\hline & $\begin{array}{l}\text { First row of } \\
\text { upstream }\end{array}$ & & & 111.5 & 111.9 & 124.0 & 127.3 & 129.5 & 130.7 & 131.2 & 131.2 \\
\hline & $\begin{array}{l}\text { Second row of } \\
\text { upstream }\end{array}$ & & & 109.3 & 110.2 & 120.7 & 123.4 & 125.7 & 127.2 & 127.5 & 127.5 \\
\hline \multirow{4}{*}{$\begin{array}{c}\text { Bolts' } \\
\text { axial } \\
\text { forces of } \\
\text { crane } \\
\text { beam } / \mathrm{KN}\end{array}$} & $\begin{array}{c}\text { Third row of } \\
\text { upstream }\end{array}$ & & & 61.6 & 61.6 & 61.7 & 61.8 & 62.0 & 62.2 & 62.6 & 63.1 \\
\hline & $\begin{array}{l}\text { First row of } \\
\text { downstream }\end{array}$ & & & 98.3 & 103.6 & 103.7 & 103.8 & 105.5 & 105.7 & 106.9 & 106.9 \\
\hline & $\begin{array}{c}\text { Second row of } \\
\text { downstream }\end{array}$ & & & 98.3 & 102.5 & 103.6 & 103.7 & 103.8 & 105.5 & 105.7 & 106.9 \\
\hline & $\begin{array}{l}\text { Third row of } \\
\text { downstream }\end{array}$ & & & 37.4 & 37.4 & 37.5 & 37.5 & 37.6 & 37.6 & 37.7 & 37.9 \\
\hline
\end{tabular}

What we can conclude from Table 3 are as follows, crane beam load has little effect on the overall stability of surrounding rock, and the influence is focus on areas near the crane beam. During the normal operation, the maximal displacement increment of upstream surrounding rock is $0.27 \mathrm{~mm}$, and that of downstream surrounding rock is $0.38 \mathrm{~mm}$. During the overload operation, the maximal displacement increment of upstream surrounding rock is only $0.28 \mathrm{~mm}$, and that of downstream surrounding rock is only $0.40 \mathrm{~mm}$. The displacements of surrounding rock and bolts' axial forces during the normal operation and overload operation are both roughly the same with those without load. Therefore, the displacements of surrounding rock and bolts' axial forces of crane beam are mainly caused by excavation, and parts caused by the wheel pressure are small.

\section{Conclusion}

(1) Four support schemes of the hydropower station are analyzed using the bolt element and equivalent anchoring formula of $\mathrm{FLAC}^{3 \mathrm{D}}$, from the comprehensive consideration of cavities' stabilities and economic benefits, scheme 3 ( bolts and nineteen cables ) is the optimal supporting plan, apt to ensure the overall stability of surrounding rock.

(2) After the caverns 'excavation, due to the large excavation span and height, the main powerhouse and tail water hole have larger plastic zones, and the same as 1 \# unit and 2 \# unit affected by the alteration belt; the plastic zones of the main powerhouse and main transformer hole appear connected and it is reduced obviously after support; the plastic zones of 3 \# unit and 4 \# unit are relatively small.

(3) The displacements of surrounding rock and bolts' axial forces of crane beam are mainly caused by excavation, and parts caused by the wheel pressure are small, and they are both in the engineering allowable range, so the support scheme of crane beam is reasonable. 


\section{References}

[1] H.L. Zhang, X.Z. Fu. Hygrothermal absorption and desorption of deep underground hydropower station envelops. Tunnelling and Underground Space Technology, 2011, 26(2): 398-405.

[2] N.W. Xu, C.A. Tang, L.C. Li, Z. Zhou, C. Sha, Z.Z. Liang, J.Y. Yang. Microseismic monitoring and stability analysis of the left bank slope in Jinping first stage hydropower station in southwestern China. International Journal of Rock Mechanics and Mining Sciences, 2011, 48(6): 950-963..

[3] W.S. Zhu, X.J. Li, Q.B. Zhang, W.H. Zheng, X.L. Xin, A.H. Sun, S.C. Li. A study on sidewall displacement prediction and stability evaluations for large underground power station caverns. International Journal of Rock Mechanics and Mining Sciences, 2010, 47(7): 1055-1062.

[4] Li Jia-kun. Research on Prospect and Problem for Hydropower Development of China. Procedia Engineering, 2012, 28: 677-682.

[5] LI Jing-long, LI Shu-chen, LI Li-ping. Study on Safety of Anchored Discontinuous Jointed Rock Mass Stability in Hydropower Energy Development. 2011, 5: 2054-2058.

[6] Einar Broch, Arne M. Myrvang, Gisle Stjern. Support of large rock caverns in Norway. Tunnelling and Underground Space Technology, 1996, 11(1): 11-19.

[7] John S. Anagnostopoulos, Dimitris E. Papantonis. Study of pumped storage schemes to support high RES penetration in the electric power system of Greece. Energy, 2012, 45(1): 416-423.

[8] Ming Chen, Wenbo Lu, Changping Yi. Blasting vibration criterion for a rock-anchored beam in an underground powerhouse. Tunnelling and Underground Space Technology, 2007, 22(1): 69-79.

[9] Mingdao Yuan, Ming Xiao, Ling Li. Cracks cause analysis and research on the crane rail beam of Zhanjiang plant coal wharf port. Procedia Engineering, 2012, 31: 520-527. 